\title{
Relationship of Health Locus of Control with Breast Cancer Screening Belief of Iranian Women
}

\author{
Marzieh Saei Ghare Naz', Tayebeh Darooneh ${ }^{1}$, Fatemeh Salmani², Farhnaz \\ Kholosi Badr³ ${ }^{3}$, Giti Ozgoli*
}

\begin{abstract}
Promoting breast cancer screening (BCS) behavior of women can lead to a reduction in mortality. The health locus of control affects cancer screening behavior of women; however, there is not sufficient evidence regaring this issue in Iran. The overall goal of our study is to determine the relationship of the health locus of control with the breast cancer screening belief of Iranian Women. This is a cross-sectional study carried out on 325 women in Tehran. The Multidimensional Health Locus of Control (MHLC), Breast Cancer Screening Belief Questionnaire (BCSBQ), and Demographic questionnaire were used for collecting data. Statistical analyze was performed by the SPSS version 17 software. The Pearson correlation and regression model were used for data analyze. In this study, 325 women, age 18 to 75 years, participated in this study. The mean \pm SD of BCSBQ and MHLC score was $40.72 \pm 10.41$ and $67.78 \pm 17.67$ respectively. The regression analysis showed that for the one-unit increase in the Internal Health Locus of Control (IHLC), Powerful others Health Locus of Control (PHLC), and Chance Health Locus of Control (CHLC) score (dimensions of Health Locus of Control), the total BCSBQ scores increased 0.54, 0.31, and 0.57 respectively. For each unit increase in age and education, the knowledge and perceptions of the $\mathrm{BC}$ score increased 0.05 and 0.23 units respectively. For the one-unit increase in the IHLC, PHLC, age, and education dimensions, the attitudes towards the general health checkup score increased $0.17,0.1,0.05$, and 0.188 respectively. The current study provided new insights about the BCSB of Iranian women with MHLC. In the study, all the dimensions of the health locus of control were useful in predicting the breast cancer screening belief of the participants.
\end{abstract}

Keywords: Breast cancer- screening- health locus of control

Asian Pac J Cancer Prev, 20 (3), 699-703

\section{Introduction}

Breast cancer $(\mathrm{BC})$ is the most common cancer among all women worldwide (Mahdavifar et al., 2016). The incidence of breast cancer in Iranian women is 22.6 per 100,000 (Jazayeri et al., 2015), causing a heavy health and economic burden (Daroudi et al., 2015). The stage of diagnosis is a main predictor of breast cancer survival, and the earlier the diagnosis, the better the patient's chance of survival becomes (Bamidele et al., 2017). However, most breast cancer cases are diagnosed in the advanced stages in Iran (Mohaghegh et al., 2014). One reason is the lack of participation in breast cancer screening (BCS) programs, which lead to a delayed diagnosis (Kwok et al., 2016b).

Hence, promoting the BCS behavior of women can lead to a reduction in mortality (Murray and McMillan, 1993), and social-level factors including social support and hope can help promote this behavior (Mishra et al., 2012). Another factor that affects the screening behavior of women is breast cancer perceived risk (Zhang et al.,
2011). Women's participation in breast cancer screening programs can help predict the health belief and illness attitude of women (Lostao et al., 2001). Also, a woman's sense of fear and health belief about BC could influence her readiness to participate in BCS programs (Ersin et al., 2015) and in one study it has been reported that the health locus of control affects the health behavior of women (Williams-Piehota et al., 2004). The health locus of control is the extent of perception that each person has about the source of regulating of one's health (Wallston et al., 1978), and the multidimensional health locus of control indicates the perception people have about their internal health locus of control, powerful others, and chance health locus of control (Wallston and Wallston, 1981).

Evidence has shown that cancer screening behavior could be predicted by an individual's health locus of control (Hallal, 1982). Some evidence has shown that belief about health control is a determinant factor for screening behavior (Bundek et al., 1993). It seems that one's belief in internal health control leads to better

${ }^{1}$ Student Research Committee, ${ }^{3}$ North Tehran Health Center, ${ }^{4}$ Behavioral Sciences Research Center, Shahid Beheshti University of Medical Sciences, Tehran, ${ }^{2}$ Department of Epidemiology and Biostatistics, School of Health, Birjand University of Medical Sciences, Birjand, Iran.*For Correspondence: g.ozgoli@gmail.com 
health behavior (Helmer et al., 2012); however, chance or powerful others health locus of control could lead to poor health outcomes (Grotz et al., 2011, Kuwahara et al., 2004). One study has reported that strong IHLC leads to healthier behaviors in individuals (Luszczynska and Schwarzer, 2005, Wallston, 2005). Another study has reported that external powerful others health locus of control leads to an individual's improved knowledge about health (Zaky, 2016). Several studied have shown that the health locus of control can predict cancer screening behavior (Adebimpe and Oladimeji, 2014), but in another study the opposite was proven (Tahmasebi and Noroozi, 2016) (Sahraee et al., 2013).

In Iran, most women do not receive sufficient or regular breast cancer screening (Enjezab, 2016, Farzaneh et al., 2017, Aminisani et al., 2016). Powerful cultural beliefs (Khazaee-pool et al., 2014), the health beliefs of health worker (Shiryazdi et al., 2014), perceived selfefficacy (Fouladi et al., 2013), and other different factors affect the BCS behavior of Iranian women. In fact, the health locus of control can effect health beliefs, but there is no evidence about the relationship of BCSB and MHLC in Iran. To find out the current status of this issue in Iran and for optimizing breast cancer screening programs as well as helping to maintain and improve the health of women at risk for this disease, the overall goal of our study is to determine the relationship of the health locus of control with the breast cancer screening belief of Iranian women.

\section{Materials and Methods}

This is a cross-sectional study that was carried out on selected health centers of Shahid Beheshti Medical University in June to October 2017. This study was carried out after approval from the ethic committee of Shahid Beheshti Medical University (ethics code: IR.SBMU. RETECH.REC.1396.172). An informed consent form was obtained from all participants. The sample size for this study was calculated at $325(\alpha=0.05)$. The inclusion criterion for this study was all Iranian females above 18 years of age.

The study tools were:

1) Multidimensional Health Locus of Control (MHLC) scales with 18 items. This scale assesses health related beliefs of people (Moshki et al., 2007), and includes six items about internal HLC (belief that one's state of health depends on one's own behaviors and actions), six items about powerful others HLC (belief that one's state of health depends on powerful others mainly professionals), and six items about chance HLC (belief that one's state of health is a matter of chance). Each subscale has six-point Likert choices. The total score ranges from 6 to 36, and in this scale a high score is related to the high importance of the participant's health locus of control. The Persian version of this model is valid and reliable in Iran (Moshki et al., 2007). In this study, the Cronbach's alpha is 0.799 .

2) Breast cancer screening belief questionnaire (BCSBQ) with 12 items, in which four items are about attitudes towards general health, four items are about knowledge and perceptions of $\mathrm{BC}$, and four items are about barriers to screening. All items have Likert choices ranging from strong disagreement $=1$ point to strong agreement $=5$ points, and the total score range is $(5-60)$. In this scale, the high score shows a strong attitude, high level of knowledge and perceived barriers for BCS. In this study the Cronbach's alpha is 0.818 .

3) Demographic questionnaire that includes collecting information on age, married status, educational level, employment status, economic status, and number of children.

Statistical analyze was performed by the SPSS version 17 software (SPSS Inc., Chicago, IL). The descriptive analysis was used for the description of the participants' characteristics. The Pearson correlation and linear regression model were used for evaluating the relation between independent variables and our dependent quantitative variable. P-value $<0.05$ was consider significant.

\section{Results}

In this study, 325 women (age range: $18-75$ years) participated, and most (36.1\%) had a high school diploma, good economic status (77.8\%), married (80\%), and were homemakers $(86.4 \%)$. Table 1 shows the demographic characteristics of the study participants. The mean \pm SD of the BCSB and MHLC score was 40.72 \pm 10.41 and $67.78 \pm 17.67$ respectively. The mean \pm SD of the IHLC, PHLC, and CHLC were $22.92 \pm 6.94,21.51 \pm 6.34$, and $23.33 \pm 7.33$ respectively. The lowest mean score was allocated to the attitude item about BCS (12.07 \pm 4.49$)$, and the highest mean score was allocated to the knowledge

Table 1. The Demographic Characteristics of Women Participated in Study

\begin{tabular}{lc}
\hline Variable & $34.82 \pm 11.73$ \\
\hline Age (yr.)* & $1.97 \pm 1.30$ \\
Number of children* & $14.40 \pm 11.28$ \\
Marriage duration (yr.)* & \\
Education level** & $36(11.1)$ \\
$\quad$ Illiterate & $100(30.9)$ \\
Under diploma & $117(36.1)$ \\
Diploma & $71(21.91)$ \\
Academic & \\
Marriage status $* *$ & $260(80)$ \\
Married & $48(14.8)$ \\
Single & $9(2.8)$ \\
Widowed & $8(2.5)$ \\
Divorced & \\
Employment status $* *$ & $280(86.4)$ \\
Housewife & $44(13.6)$ \\
Employed & \\
Economic status** & $17(5.2)$ \\
Good & $252(77.8)$ \\
Intermediate & $55(17)$ \\
Poor & \\
\hline
\end{tabular}

*, Data presented as Mean $\pm \mathrm{SD}$;**, Data presented as N (\%). 
Table 2. The Correlation between Breast Cancer Screening Belief Subscales and Multidimensional Health Locus of Control (MHLC) Scales

\begin{tabular}{|c|c|c|c|}
\hline Variable & $\begin{array}{l}\text { Internal Health } \\
\text { locus of control }\end{array}$ & $\begin{array}{l}\text { Powerful others Health } \\
\text { locus of control }\end{array}$ & $\begin{array}{c}\text { Chance Health locus } \\
\text { of control }\end{array}$ \\
\hline \multirow[t]{2}{*}{ Attitudes towards general health check-ups } & $\mathrm{R}=0.41$ & $\mathrm{R}=0.28$ & $\mathrm{R}=0.37$ \\
\hline & $\mathrm{P}=0.001$ & $\mathrm{P}=0.001$ & $\mathrm{P}=0.001$ \\
\hline \multirow[t]{2}{*}{ Knowledge and perceptions of BC } & $\mathrm{R}=0.84$ & $\mathrm{R}=-0.008$ & $\mathrm{R}=0.086$ \\
\hline & $\mathrm{P}=0.13$ & $\mathrm{P}=0.88$ & $\mathrm{P}=0.12$ \\
\hline \multirow[t]{2}{*}{ Barriers to screening } & $\mathrm{R}=0.32$ & $\mathrm{R}=0.148$ & $\mathrm{R}=0.43$ \\
\hline & $\mathrm{P}=0.001$ & $\mathrm{P}=0.007$ & $\mathrm{P}=0.001$ \\
\hline
\end{tabular}

item about BCS (15.23 \pm 3.92$)$.

According the correlation analyze, there were positive significant correlations between the attitudes towards general health check-up dimension of the BCSBQ with the internal HLC $(\mathrm{R}=0.41, \mathrm{P}=0.001)$, powerful HLC $(\mathrm{R}=0.28, \mathrm{P}=0.001)$, and chance $\operatorname{HLC}(\mathrm{R}=0.37, \mathrm{P}=0.001)$. Also, there were positive significant correlations between the barriers to the screening dimension of the BCSBQ with the internal $\mathrm{HLC}(\mathrm{R}=0.32, \mathrm{P}=0.001)$, powerful HLC $(\mathrm{R}=0.148, \mathrm{P}=0.007)$, and chance $\operatorname{HLC}(\mathrm{R}=0.43, \mathrm{P}=0.001)$. No significant association was reported between the knowledge and perceptions of $\mathrm{BC}$ items and the three dimensions of the MHLC (Table 2).

The regression analyzes showed that for the one-unit increase in IHLC (R2=13\%), PHLC (R2=3\%), and CHLC $(\mathrm{R} 2=16 \%)$, in the score of dimensions of the health locus of control, the total BCSBQ scores increased 0.54, 0.31, and 0.57 respectively. For each unit increase in age and education, the knowledge and perceptions of the $\mathrm{BC}$ score increased 0.05 and 0.23 units respectively. For one-unit increases in the IHLC, PHLC, age, and education, the attitudes towards the general health check-up score increased $0.17,0.1,0.05$, and 0.188 respectively.

For each unit increase in the IHLC, CHLC, age and education deminsions, the barriers to screening score increased $0.11,0.27,0.08$, and 0.28 respectively. However, for each unit increase in the PHLC, the barriers to screening score decreased 0.15 .

\section{Discussion}

The result of our study showed that there was a significant association between breast cancer screening beliefs of women with the three dimensions of the MHLC. In this study, the mean score of IHLC and CHLC were close, and the lowest score was related to the powerful others health locus of control.

Similar to our study, in Rowe et al.,'s (2005) study, the internal HLOC have a significant relationship with breast cancer-specific control (Rowe et al., 2005). Adebimpe and Oladimeji (2014) demonstrated that the internal locus of control predicted cervical cancer screening behavior of women. Nonetheless, in Tahmasebi and Noroozi (2016) study, the health locus of control did not predict the BSE

Table 3. Regression Model for Predictor Variable of BCSBQ Score and Its Subgroup Items

\begin{tabular}{llccccc}
\hline Dependent variable & Model & B & Std. Error & Beta & t & Sig \\
\hline BCSBQ & IHLC & 0.54 & 0.07 & 0.36 & 7.02 & 0.001 \\
& PHLC** & 0.31 & 0.09 & 0.19 & 3.47 & 0.001 \\
& CHLC*** & 0.57 & 0.07 & 0.406 & 7.97 & 0.001 \\
Knowledge and perceptions of BC & IHLC & 0.04 & 0.04 & 0.078 & 1.05 & 0.29 \\
& PHLC & -0.05 & 0.04 & -0.09 & -1.25 & 0.21 \\
& CHLC & 0.02 & 0.03 & 0.04 & 0.63 & 0.52 \\
Attitudes towards general health check-ups & Age (year) & 0.05 & 0.01 & 0.16 & 2.9 & 0.004 \\
& Education (year) & 0.23 & 0.05 & 0.27 & 4.7 & 0.001 \\
& IHLC & 0.17 & 0.04 & 0.27 & 4.07 & 0.001 \\
& PHLC & 0.005 & 0.04 & 0.007 & 0.11 & 0.91 \\
& CHLC & 0.105 & 0.04 & 0.17 & 2.55 & 0.011 \\
& Age (year) & 0.05 & 0.02 & 0.13 & 2.44 & 0.015 \\
& Education (year) & 0.188 & 0.052 & 0.19 & 3.6 & 0.001 \\
& IHLC & 0.11 & 0.47 & 0.16 & 2.49 & 0.013 \\
& PHLC & -0.15 & 0.5 & -0.19 & -3.05 & 0.002 \\
& CHLC & 0.27 & 0.04 & 0.4 & 6.35 & 0.001 \\
& Age (year) & 0.08 & 0.022 & 0.202 & 3.97 & 0.001 \\
& Education (year) & 0.285 & 0.056 & 0.26 & 5.12 & 0.001 \\
\hline
\end{tabular}

*, Internal Health locus of control; **, Powerful others Health locus of control; ***, Chance Health locus of control 
behavior of women. Holm et al., (1999) reported that a heath belief model and health locus control did not predict the BCS behavior of women. Also, in Sahraee et al.,'s (2013) study, the locus of control did not predict the breast self-examination behavior of women. In a study on deaf women, Wang et al., (2010) reported that the internal health locus of control did not predict their cervical cancer knowledge.

Women's sense about their health control is affected by their beliefs (Epstein, 2014). Belief is a cognitive factor that has a key role on perceived risk of disease (Tilburt et al., 2011). It seems that one of the reasons for the controversy between the results of these studies is the variation found in the studied populations that also have cultural differences.

Our result showed that the lowest mean score was allocated to the attitude about BCS and the highest mean score was allocated to the knowledge about BCS. Kawar et al., (2009) reported that knowledge of women about BCS was at mid-level, but their belief about using BCS was high. In Tilaki 's (2015) study done in Northern Iran, there was a low level of awareness and practice of BCS. In another study done on the female personnel of Walailak University, the knowledge of BCS was very high (Kotepui et al., 2015). The main barrier for cancer screening is the low level of cancer awareness (Kadam et al., 2016). Usually positive changes in the attitude of people occur as a result of increasing awareness and their education.

In this study, age and level of education were the positive predictor variables of knowledge and perceptions of BC that influenced the attitudes towards general health check-ups, and barriers to the screening dimension of breast cancer screening beliefs. Similar to our study, Kwok et al., (2016a) reported that Arabic-Australian women with higher educational levels had significantly higher scores in the three dimensions of the BCSBQ. In Kim et al.,'s (2014) study, the education level predicted the BCS behavior of Korean women. One study in African-American women demonstrated that there was no association between health beliefs and education years (Barroso et al., 2000). Higher levels of education lead to increasing awareness about each subject, and this can also affect the health belief of people and assist them in adopting good health practices. Higher education levels lead to greater access to health information and this can also affect their belief in the type of health locus of control. Also, people who are older usually have more life experience and make better self-informed choices than other age groups, and this can also positively affect their health beliefs. In our study, all dimension of the health locus of control predicted the three dimensions of the BCSBQ. In Hashemian et al.,'s (2015) study, there was not a significant relationship between attitude about breast cancer and all the dimensions of the health locus of control (belief in internal health locus of control, belief in chance, belief in other people). Beliefs are part of the attitude and knowledge of individuals and it can also affect one's belief in the type of health source of control. To reduce the breast cancer morbidity and mortality psychological attributions and time of seeking help is very important (Attari et al., 2016).

Our study provided new insights about the BCSB of
Iranian women with MHLC. By knowing the health belief of women, we can design an intervention to influence their beliefs. However, further qualitative studies are needed to examine these concepts.

\section{Limitation}

In this study all data were obtained by self-reported questionnaires, so different factors could affect them.

In Conclusion, in our population study, all dimensions of the health locus of control were able to help predict the study participants' breast cancer screening beliefs.

\section{Conflict of interest}

The authors declare they have no conflicts of interest.

\section{Acknowledgments}

The all author thanks from all women participated in this study; also we gratefully acknowledge Behavioral Sciences Research Center of Shahid Beheshti Medical University.

\section{References}

Adebimpe OA, Oladimeji BY (2014). Health beliefs and locus of control as predictors of cancer screening behaviour among women in Obafemi Awolowo University community. Gend Behav, 12, 6457-64.

Aminisani N, Fattahpour R, Dastgiri S, Asghari-Jafarabadi M, Allahverdipour H (2016). Determinants of breast cancer screening uptake in Kurdish women of Iran. Health Promot Perspect, 6, 42.

Attari SM, Ozgoli G, Solhi M, Majd HA (2016). Study of relationship between illness perception and delay in seeking help for breast cancer patients based on leventhal's self-regulation model. Asian Pac J Cancer Prev, 17, 167-74.

Bamidele O, Ali N, Papadopoulos C, Randhawa G (2017). Exploring factors contributing to low uptake of the NHS breast cancer screening programme among Black African women in the UK. Divers Equal Health Care, 14, 212-9.

Barroso J, Mcmillan S, Casey L, et al (2000). Comparison between African-American and white women in their beliefs about breast cancer and their health locus of control. Cancer Nurs, 23, 268-76.

Bundek NI, Marks G, Richardson JL (1993). Role of health locus of control beliefs in cancer screening of elderly Hispanic women. Health Psychol, 12, 193.

Daroudi R, Sari AA, Nahvijou A, et al (2015). The economic burden of breast cancer in Iran. Iran J Public Health, 44, 1225 .

Enjezab B (2016). Cancer screening practice among Iranian Middle-aged women. J Midwifery Reprod Health, 4, 770-8.

Epstein L (2014). The influence of perceived control on breast cancer screening in Hispanic/latino women. Master thesis of Public Health (MPH), Yale University.

Ersin F, Gozukara F, Polat P, Ercetin G, Bozkurt ME (2015). Determining the health beliefs and breast cancer fear levels ofwomen regarding mammography. Turk J Med Sci, 45, 775-81.

Farzaneh E, Hedydari H, Shekarchi AA, Kamran A (2017). Breast and cervical cancer-screening uptake among females in ardabil, northwest iran: a community-based study. Onco Targets Ther, 10, 985.

Fouladi N, Pourfarzi F, Mazaheri E, et al (2013). Beliefs and 
behaviors of breast cancer screening in women referring to health care centers in northwest Iran according to the champion health belief model scale. Asian Pac J Cancer Prev, 14, 6857-62.

Grotz M, Hapke U, Lampert T, Baumeister H (2011). Health locus of control and health behaviour: results from a nationally representative survey. Psychol Health Med, 16, $129-40$.

Hallal JC (1982). The relationship of health beliefs, health locus of control, and self concept to the practice of breast selfexamination in adult women. Nurs Res, 31, 137-42.

Hashemian M, Fallahi A, Akaberi A, et al (2015). Relationship of health locus of control with attitude toward breast cancer among women with family positive history of breast cancer in Sabzevar city (2014). IJOGI, 18, 9-15.

Helmer SM, Kramer A, Mikolajczyk RT (2012). Health-related locus of control and health behaviour among university students in North Rhine Westphalia, Germany. BMC Res Notes, 5, 703.

Holm CJ, Frank DI., Curtin J (1999). Health beliefs, health locus of control, and women's mammography behavior. Cancer Nurs, 22, 149-56.

Jazayeri SB, Saadat S, Ramezani R, Kaviani A(2015). Incidence of primary breast cancer in Iran: Ten-year national cancer registry data report. Cancer Epidemiol, 39, 519-27.

Kadam YR, Quraishi SR, Dhoble RV, Sawant MR, Gore AD (2016). Barriers for early detection of cancer amongst urban Indian women: a cross sectional study. Iran J Cancer Prev, 9, e3900.

Kawar LN (2009). Jordanian and Palestinian immigrant women's knowledge, affect, cultural attitudes, health habits, and participation in breast cancer screening. Health Care Women Int, 30, 768-82.

Khazaee-Pool M, Majlessi F, Foroushani AR, et al (2014). Perception of breast cancer screening among Iranian women without experience of mammography: a qualitative study. Asian Pac J Cancer Prev, 15, 3965-971.

Kim J, Lee SK, Lee J, et al (2014). Breast cancer screening knowledge and perceived health beliefs among immigrant women in Korea. J Breast Cancer, 17, 279-86.

Kotepui M, Piwkham D, Chupeerach C, Duangmano S (2015). Knowledge, attitudes and practice of breast cancer screening among female personnel of Walailak University. Health Expect, 18, 3069-78.

Kuwahara A, Nishino Y, Ohkubo T, et al (2004). Reliability and validity of the multidimensional health locus of control scale in Japan: relationship with demographic factors and health-related behavior. Tohoku J Exp Med, 203, 37-45.

Kwok C, Endrawes G, Lee CF (2016a). Breast cancer screening beliefs questionnaire: psychometric properties assessment of the Arabic version. Eur J Oncol Nurs, 20, 42-8.

Kwok C, Ogunsiji O, Lee CF (2016b). Validation of the breast cancer screening beliefs questionnaire among African Australian women. BMC Public Health, 16, 117.

Lostao L, Joiner TE, Pettit JW, Chorot P, Sandin B (2001). Health beliefs and illness attitudes as predictors of breast cancer screening attendance. Eur J Public Health, 11, 274-9.

Luszczynska A, Schwarzer R (2005). Multidimensional health locus of control: comments on the construct and its measurement. $J$ Health Psychol, 10, 633-42.

Mahdavifar N, Pakzad R, Ghoncheh M, Pakzad I, et al (2016). Spatial analysis of breast cancer incidence in Iran. Asian Pac J Cancer Prev, 17, 59-64.

Mishra SI, Deforge B, Barnet B, Ntiri S, Grant L (2012). Social determinants of breast cancer screening in urban primary care practices: a community-engaged formative study. Womens Health Issues, 22, 429-38.
Mohaghegh P, Yavari P, Akbari ME, Abadi A, Ahmadi F (2014). The correlation between the family levels of socioeconomic status and stage at diagnosis of breast cancer. Iran J Cancer Prev, 7, 232.

Moshki M, Ghofranipour F, Hajizadeh E, Azadfallah P (2007). Validity and reliability of the multidimensional health locus of control scale for college students. BMC Public Health, 7, 295.

Murray M, Mcmillan C (1993). Health beliefs, locus of control, emotional control and women's cancer screening behaviour. Br J Clin Psychol, 32, 87-100.

Rowe JL, Montgomery GH, Duberstein PR, Bovbjerg DH (2005). Health locus of control and perceived risk for breast cancer in healthy women. Behav Med, 31, 33-42.

Sahraee A, Noroozi A, Tahmasebi R (2013). Predicting factors of breast self-examination based on health belief model and locus of control among women aged 20-50 years. $J$ Hayat, 19, 27-39.

Shiryazdi SM, Kholasehzadeh G, Neamatzadeh H, Kargar S (2014). Health beliefs and breast cancer screening behaviors among Iranian female health workers. Asian Pac J Cancer Prev, 15, 9817-22.

Tahmasebi R, Noroozi A (2016). Is health locus of control a modifying factor in the health belief model for prediction of breast self-examination?. Asian Pac J Cancer Prev, 17, 2229-33.

Tilaki KH, Auladi S (2015). Awareness, attitude, and practice of breast cancer screening women, and the associated socio-demographic characteristics, in Northern Iran. Iran J Cancer Prev, 8, e3429.

Tilburt JC, James KM, Sinicrope PS, et al (2011). Factors influencing cancer risk perception in high risk populations: a systematic review. Hered Cancer Clin Pract, 9, 2.

Wallston KA(2005). The validity of the multidimensional health locus of control scales. J Health Psychol, 10, 623-31.

Wallston KA, Strudler Wallston B, Devellis R (1978). Development of the multidimensional health locus of control (MHLC) scales. Health Educ Monogr, 6, 160-70.

Wallston KA, Wallston BS (1981). Health locus of control scales. Research with the locus of control construct, 1, pp 189-243.

Wang R, Aldridge AA, Malcarne VL, et al (2010). Health locus of control and assimilation of cervical cancer information in deaf women. J Cancer Educ, 25, 354-9.

Williams-Piehota P, Schneider TR, Pizarro J, Mowad L, Salovey $P(2004)$. Matching health messages to health locus of control beliefs for promoting mammography utilization. Psychol Health, 19, 407-23.

Zaky NH (2016). The relationship between health locus of control, knowledge and adherence to antihypertensive regimen among woman with preeclampsi. Am J Nurs Res, 4, 41-50.

Zhang LR, Chiarelli AM, Glendon G, et al (2011). Influence of perceived breast cancer risk on screening behaviors of female relatives from the Ontario site of the Breast Cancer Family Registry. Eur J Cancer Prev, 20, 255.

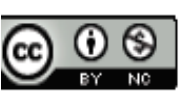

This work is licensed under a Creative Commons AttributionNon Commercial 4.0 International License. 